\title{
Extraintestinal salmonellosis
}

\author{
By E. G. L. WILKINS AND C. ROBERTS \\ Public Health Laboratory, Fazakerley Hospital, Lower Lane, Liverpool L9 7AL
}

(Accepted 8 January 1988)

\section{SUMMARY}

Between 1969 and 1984, 6564 non-typhoid salmonella strains were isolated at the Liverpool Public Health Laboratory of which $194(3.0 \%)$ were from extraintestinal sites. Blood $(34 \%)$ and urine $(32 \%)$ isolates accounted for twothirds of these, with the remainder being recovered from pus and inflammatory tissue $(23 \%)$, bone $(5 \%)$, cerebrospinal fluid $(5 \%)$ and sputum $(3 \%)$. Certain serotypes tended to cause more invasive disease than others, i.e. Salmonella choleraesuis, S. dublin, S. london, S. virchow and S. panama: this association for $S$. london has not previously been described. The spectrum of disease caused by non-typhoid strains was broad. This survey confirms the importance of nontyphoid salmonellas as occasional causes of invasive disease and local sepsis outside the gastrointestinal tract.

\section{INTRODUCTION}

Salmonella infection of man can be broadly divided into five clinical groups: enteric fever, septicaemia without localization, focal disease (with or without associated bacteraemia), gastroenteritis, and the carrier state (Saphra \& Winter, 1957). Most salmonella species are probably capable of producing any of these syndromes, but certain serotypes are associated with certain presentations; e.g. Salmonella typhimurium with gastroenteritis, S. choleraesuis with septicaemia, and $S$. typhi with enteric fever and the carrier state. This behaviour reflects the inherent virulence of each species, the typhoid salmonellas (S. typhi and $S$. paratyphi) and S. choleraesuis being the most invasive in the immunecompetent host. Several other factors contribute to the pathogenesis of salmonellosis and an increased susceptibility to invasive disease may result from an alteration of locally protective mechanisns, e.g. gastric acid, presence of diseased tissue, e.g. bone infarcts, or impairment of the immune system, e.g. human immunodeficiency virus infection. In these circumstances, the non-typhoid salmonellas may behave in a similar fashion to $S$. typhi and such patients often present with clinically invasive disease. Of therapeutic importance in this situation is the increasingly frequent association of multiple drug resistance with non-typhoid strains of salmonella. In $1985,20 \%$ of $S$. typhimurium isolates from humans were resistant to two or more antibiotics (Rowe \& Threlfall, 1986).

The incidence of typhoid and paratyphoid in England and Wales is low and declining (approximately 300 cases/year) and is usually contracted abroad 
(Communicable Disease Surveillance Centre [CDSC], 1983). In contrast, the number of reported cases of non-typhoid salmonella infection remains high (13201 in 1984) and usually results from indigenously acquired infection (CDSC, 1987). Hence, although invasive disease complicating non-typhoid salmonellosis is uncommon, in our experience it is more likely to be observed in this country than typhoid and paratyphoid.

While the knowledge that certain serotypes may produce a particular clinical syndrome could assist the clinician in diagnosis and therapy, we believe that the prevalence and clinical significance of invasive salmonellosis due to non-typhoid salmonella infection is often not appreciated. Therefore, we have reviewed all bacteriologically proven cases of non-typhoid salmonellosis admitted to this hospital between 1969 and 1984 .

\section{PATIENTS AND METHODS}

The bacteriological records and case notes of all patients admitted to the hospital with a possible diagnosis of extraintestinal salmonellosis between January 1969 and December 1983 were examined. All samples, i.e. faeces, rectal swabs, blood, urine, pus or pus swabs, cerebrospinal fluid (CSF), bone tissue, sputum and post-mortem material were examined by standard methods. Colonies suspected of being salmonellas were subcultured from blood agar, deoxycholate citrate agar, MacConkey agar or Wilson and Blair's medium and identified biochemically and serologically. The precise identity of the salmonellas was confirmed by the Division of Enteric Pathogens, the Central Public Health Laboratory, Colindale, London.

\section{RESULTS}

During the 15 years under study a total of 6564 non-typhoid salmonella strains were isolated of which $194(3.0 \%)$ were from extraintestinal sites (Table 1). The annual number of total isolates ranged from 279 to 845 and of extraintestinal isolates from 7 to 22 .

In two cases more than one serotype was isolated simultaneously from the same patient : a patient who had had a cholecystectomy was incidentally found to have $S$. agona and $S$. paratyphi B in the bile, and a patient with $S$. choleraesuis septicaemia also had $S$. enteritidis in her stools. A third patient had a dual infection with salmonella and campylobacter. Blood and urine isolates were most commonly recovered from patients in the seventh and eighth decades of life and from females more often than males. All but one of the CSF isolates and one-third of the strains from bone were from children less than 1 year of age, the majority being from boys. Cases yielding salmonellas from acutely inflamed tissue or collections of pus were evenly distributed throughout all age groups and between the sexes.

The presence of underlying disease was often difficult to determine because of incomplete information. However, of 56 patients with salmonella bacteraemia on whom information was available, $15(27 \%)$ had conditions predisposing them to invasive disease; hypochlorhydria in 6 cases (5 post-surgical, 1 pernicious 
Table 1. Source of salmonella isolates

$\begin{array}{lrc}\text { Source } & \text { No. of isolates } & \text { Total (\%) } \\ \text { Faeces } & 6370 & 97 \cdot 0 \\ \text { Blood } & 65 & 1 \cdot 0 \\ \text { Urine } & 62 & 0 \cdot 9 \\ \text { Pus } & 44 & 0 \cdot 7 \\ \text { CSF } & 9 & 0 \cdot 15 \\ \text { Bone } & 9 & 0 \cdot 15 \\ \text { Sputum } & 5 & 0 \cdot 1 \\ \text { Total } & 6564 & 100 \cdot 0\end{array}$

anaemia), reticuloendothelial disorders in 5, immunosuppressive drugs in 3 , and cirrhosis in 1.

Salmonella typhimurium was the most frequent serotype isolated from stools and from blood, urine and pus (Table 2). No particular association between serotype and site of extraintestinal disease was found, but certain serotypes did appear to cause invasive disease and local sepsis more frequently than others as indicated by the proportion of extraintestinal to total isolates. These were S. choleraesuis $(1: 1), S$. dublin $(4: 6)$, S. london $(5: 27), S$. virchow $(18: 261)$ and S. panama $(17: 268)$.

\section{Isolates from different sites}

Blood culture isolates (Table 3)

The majority of blood culture isolates $(59 \%)$ were from patients with selflimiting diarrhoea. Nevertheless, 6 patients, all of whom had underlying disease which predisposed them to invasive salmonellosis, required intensive antibiotic therapy. Of these 6, 3 had a recurrence with the same serotype after completing an initial course of treatment. In 16 patients the features of septicaemia were predominant with diarrhoea, if present, being mild and of short duration. The serotypes concerned were $S$. enteritidis (5 isolates), S. anatum and S. typhimurium (3 each), S. hadar (2) and S. panama, S. stanley and S. colindale (1 each). A further 7 patients had bacteraemia associated with culture positive focal disease involving the chest (4), spine (1), meninges (1), and a surgically removed blood clot (1). The serotypes responsible were $S$. typhimurium (2) and S. dublin, S. newport, S. hadar, S. panama and an unnamed strain (1 each).

\section{Urine culture isolates (Table 4)}

In addition to the quantitative leucocyte and bacterial urine counts, emphasis was placed upon the presence or absence of symptoms and the results of blood and stool cultures in distinguishing contamination from infection. In $27 \%$ of isolates from urine, contamination during collection from patients with acute salmonella gastroenteritis was suspected. In a further eight asymptomatic patients $(14 \%$ of isolates) the same salmonella was also isolated from the blood and its presence in urine may have been due to renal seeding or to faecal contamination.

Twenty-five patients with urinary symptoms of cystitis and one of pyelonephritis had significant levels of bacteriuria and pyuria. Approximately half of these patients had recently had or were presently suffering from diarrhoea, with 


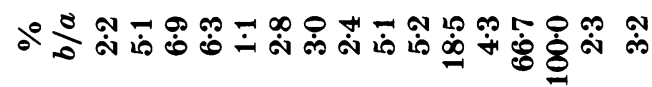
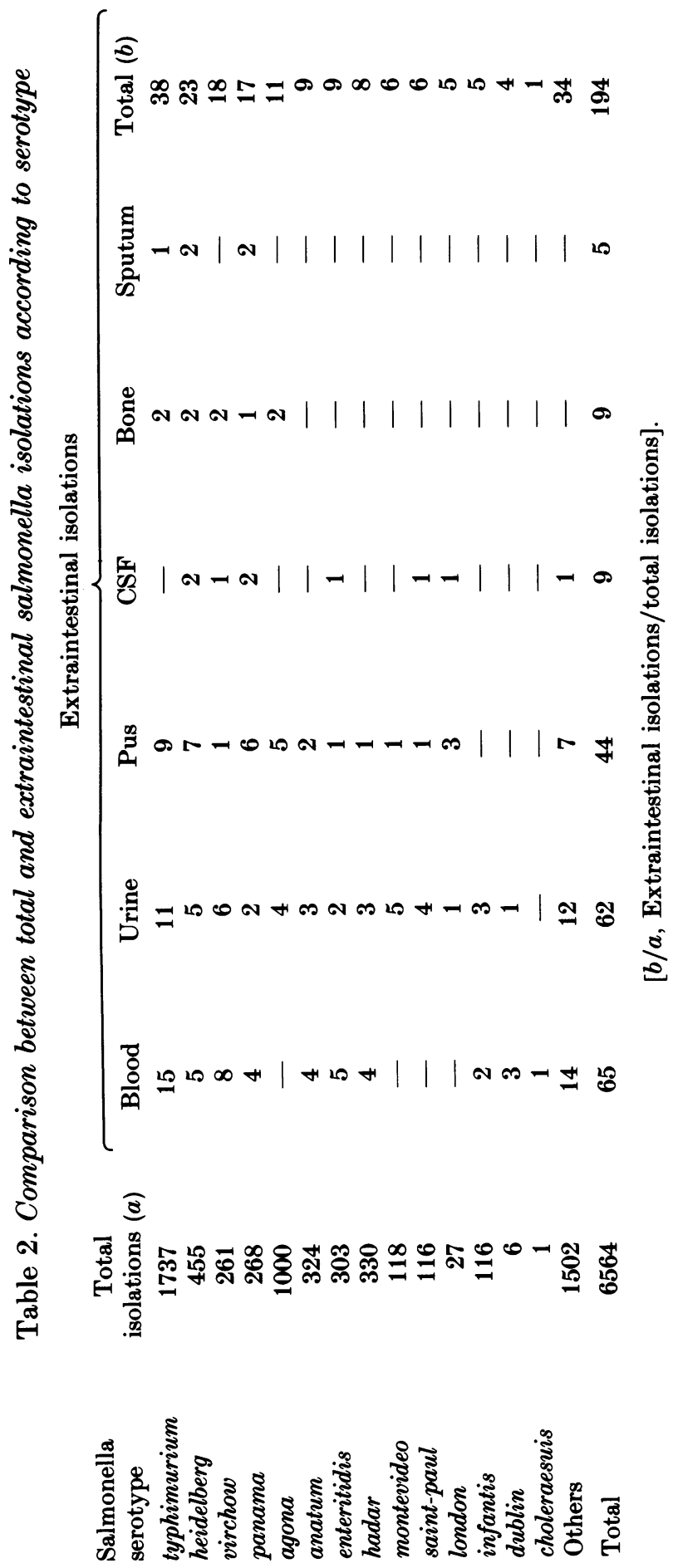
Table 3. Predominant clinical syndrome and blood culture isolates

\begin{tabular}{|c|c|c|c|}
\hline $\begin{array}{l}\text { Predominant } \\
\text { clinical syndrome }\end{array}$ & $\begin{array}{l}\text { No. of } \\
\text { isolates }\end{array}$ & $\begin{array}{l}\% \text { of total } \\
\text { analysable }\end{array}$ & Characteristic features \\
\hline Gastroenteritis & 33 & 59 & $\begin{array}{l}\text { Enteric symptoms predominant } \\
\text { Faecal culture + ve }\end{array}$ \\
\hline $\begin{array}{l}\text { Typhoid-like or } \\
\text { septicaemic }\end{array}$ & 16 & 29 & $\begin{array}{l}\text { Enteric symptoms minimal } \\
\text { Faecal culture - ve }\end{array}$ \\
\hline Focal disease & 7 & 12 & $\begin{array}{l}\text { Enteric symptoms usually } \\
\text { absent } \\
\text { Identical organism from focal } \\
\text { site } \\
\text { Faecal culture }+/-\end{array}$ \\
\hline $\begin{array}{l}\text { Insufficient } \\
\text { information }\end{array}$ & 9 & 一 & \\
\hline Total & 65 & & \\
\hline
\end{tabular}

Table 4. Predominant clinical syndrome and urine culture isolates

Predominant
clinical syndrome

Gastroenteritis; probable contamination

Gastroenteritis; possible bacteraemic seeding

Urinary tract infection With diarrhoea Without diarrhoea

Chronic carriage or asymptomatic bacteriuria Insufficient information Total

$\begin{array}{cc}\text { No. of } & \% \text { of total } \\ \text { isolates } & \text { analysable }\end{array}$

16

8

14

12

9

3

62

\section{7}

14

24

20

15

\section{Characteristic features}

Asymptomatic blood culture

- ve

Asymptomatic blood culture +ve

Symptomatic

$>10 \mathrm{WBC} / \mathrm{cu} . \mathrm{mm}$,

$>10^{5}$ organisms $/ \mathrm{ml}$.

Asymptomatic, $>10 \mathrm{WBC} / \mathrm{cu}$. mm $>10^{5}$ organisms $/ \mathrm{ml}$.

identical organisms being isolated from their faeces. The other half presented without any antecedent enteric history. In nine patients, the recovery of salmonella from urine was an incidental finding. None had a history of recent or current urinary or gastrointestinal symptoms and, of those where faecal samples were examined, none were positive. This was probably a heterogeneous group consisting of true chronic urinary carriers, patients with asymptomatic bacteriuria associated with latent bowel carriage and intermittent or low-level excretion, and contaminated samples from convalescent or asymptomatic faecal excretors.

\section{Isolates from pus (Table 2)}

Cases with acute inflammation or a collection of pus directly or indirectly connected with the abdomen accounted for 27 isolates and included patients with cholecystitis (4), peritonitis (2), and abscesses of the ischiorectum (3), spleen (1), scrotum (1), and Bartholin's glands (1). Seven post-operative wound infections also yielded salmonellas: three of the operations were for suspected appendicitis which was later diagnosed as salmonella gastroenteritis. 
Five patients had localized abscesses involving the jaw, axilla, chest wall, groin and foot, and in a further six cases infection through breached skin occurred, including one caused by a stab wound. Three infants aged less than 3 weeks were colonized following vertical transmission at birth; the sites were ear (2) and umbilicus (1). In three patients, the origin of the pus yielding salmonella had not been recorded.

\section{Other isolates (Table 2)}

Nine cases of salmonella meningitis due to a variety of serotypes were recorded. With the exception of a teenager, all isolates were from children under 1 year of age. Four patients including the teenager died.

There were nine cases of salmonella osteomyelitis-arthritis with no one serotype predominating. The infected sites were the spine in 3 cases, the sternum in 2 , and the hallux, greater trochanter, and knee in 1 each. In 1 patient the origin of the bone sample was not recorded.

Salmonellas were cultured from sputum samples and from specimens of lung or pleura obtained at post-mortem in $\mathbf{5}$ cases.

\section{DISCUSSION}

Over a period of 15 years, $194(3 \%)$ of 6564 strains of non-typhoid salmonellas were recovered from extraintestinal sites with $S$. typhimurium, $S$. heidelberg, S. virchow, and S. panama most frequently involved. Saphra \& Winter (1957) from the New York Salmonella Centre reviewed $\mathbf{7 7 7 9}$ human salmonella infections (9518 cultures, excluding $S$. typhi) and found $13.5 \%$ of isolates were from extraintestinal sites, the commonest serotypes being $S$. typhimurium, $S$. choleraesuis, and S. paratyphi B. The generally higher frequency of invasive isolates in the American study is partly due to the inclusion of $S$. paratyphi strains which were excluded in our study and the greater number of $S$. choleraesuis infections, a serotype known to be invasive but rarely isolated in the United Kingdom. Another possible factor might be a bias towards the reporting of extraintestinal isolates to a large referral centre. A study in Massachusetts published in the same year reported that only $1.4 \%$ of 2625 salmonella isolates were recovered from blood cultures (MacCready, Reardon \& Saphra, 1957), a figure much closer to our own of $1.0 \%$.

Clinically, higher rates of septicaemic or typhoid-like illness $(6 \cdot 3-16.5 \%)$ and focal disease $(2 \cdot 5-13 \cdot 1 \%)$ than those found in the present study $(0 \cdot 2$ and $1.7 \%)$ have been described by several authors (Eisenberg, Palazzolo \& Flippin, 1955; MacCready, Reardon \& Saphra, 1957; Saphra \& Winter 1957).

Isolates from blood constituted one-third of all extraintestinal salmonellas recovered, S. typhimurium being the commonest serotype involved. Most of these patients were suffering from acute self-limiting gastroenteritis, when it is probably the rule rather than the exception for otherwise healthy adults to develop a transient bacteraemia. This hospital's policy of taking blood cultures from all new patients with gastroenteritis partly accounts for the high proportion of bacteraemias identified in this category. Several investigators have calculated the ratio of blood isolates to blood-and-stool isolates for each serotype and used the 
result as a measure of the invasiveness of that serotype. Expressed as a percentage, these ratios have been highest for $S$. choleraesuis $(23 \cdot 8-62.4 \%)$ and $S$. dublin $(39.8 \%)$ and lowest for $S$. typhimurium $0 \cdot 6-5 \cdot 2 \%)$ and $S$. enteritidis $(2 \cdot 4-8 \cdot 3 \%)$, with $S$. panama occupying an intermediate position (5.8-19.9\%) (MacCready, Reardon \& Saphra, 1957; Saphra \& Winter, 1957; Cherubin et al. 1974; Blaser \& Feldman, 1981). Our findings, expressed as the percentage of extraintestinal isolates to total isolates, are very similar (Table 2). The potential invasiveness of $S$. choleraesuis, S. dublin, S. virchow, and S. panama is well described (Saphra \& Wasserman, 1954; Wermer, Humphrey \& Kamae, 1979; Blaser \& Feldman, 1981 ; Todd \% Murdoack, 1983), but for S. london has not been previously reported. However, although some serotypes may show greater virulence than others, it must be presumed that any salmonella serotype may be capable of producing invasive disease, a view supported by the large number of serotypes cited in this and other series. Of more importance in determining clinical outcome, is the age and individual susceptibility of the patient. Furthermore, the overall incidence of extraintestinal salmonellosis due to a particular serotype reflects the general prevalence of that serotype in the community which is in keeping with $S$. typhimurium being the commonest isolate recovered from extraintestinal sites despite its relatively low virulence. Several reports testify to the potential invasiveness of the serotype in the compromised host (Black, Kunz \& Swartz, 1960a; Glover, Smith \& Porter, 1982).

The spectrum of disease caused by non-typhoid salmonellas was as broad as that found with S. typhi (Hook, 1985) and included typhoid-like and septicaemic illnesses, focal manifestations such as meningitis, osteomyelitis, septic arthritis, pneumonia, cholecystitis, peritonitis, pyelonephritis and cystitis, and abscesses in various parts of the body. Bacterial endocarditis was not encountered in this study but has been reported in other series (Saphra \& Winter, 1957). Several unusual but well-recognized manifestations of salmonella infection were recorded amongst which were severe disease in the immunosuppressed, after gastric surgery and in cirrhosis (Black, Kunz \& Swartz, 1960a), gastroenteritis mimicking appendicitis (Black, Kunz \& Swartz, 1960b), simultaneous infection with two different salmonella serotypes, overt disease precipitated by antibiotics (Hardy $e t$ al. 1984), and salmonella vasculitis (Winocour et al. 1985).

It is concluded from this survey that, in the United Kingdom, non-typhoid salmonellas are an occasional cause of invasive disease and local sepsis outside the gastrointestinal tract and that certain serotypes display a greater propensity to cause invasive disease than others.

We wish to thank our clinical colleagues, particularly Dr H. Parry and Dr F. Nye, for access to the case notes of their patients. We are also grateful to Miss Karen Whalley for secretarial help.

\section{REFERENCES}

Black, P. H., Kunz, L. J. \& Swartz, M. N. (1960a). Salmonellosis - a review of some unusual aspects. New England Journal of Medicine 262, 864-870.

Black, P. H., Kunz, L. J. \& Swartz, M. N. (1960b). Salmonellosis - a review of some unusual aspects. New England Journal of Medicine 262, 921-927. 
Blaser, J. M. \& Feldman, R. A. (1981). Salmonella bacteraemia: reports to the Centre for Disease Control, 1968-1979. Journal of Infectious Diseases 143, 743-746.

Cherubin, C. E., Neu, H. C., Imperato, P. J., Harvey, R. P. \& Bellen, N. (1974). Septicaemia with non-typhoid salmonella. Medicine 53, 365-376.

Eisenberg, G. M., Palazzolo, A. J. \& Flippin, H. F. (1955). Clinical and microbiological aspects of salmonellosis. A study of ninety-five cases in adults and children. New England Journal of Medicine 253, 90-94.

Communicable Disease Surveillance Centre (1983). Typhoid fever, England and Wales 1978-82. British Medical Journal 287, 1205.

Communicable Disease Surveillance Centre (1987). Food borne disease surveillance in England and Wales 1984. British Medical Journal 293, 1424-1427.

Glover, S. C., Smith, C. C. \& Porter, I. A. (1982). Fatal salmonella septicaemia with disseminated intravascular coagulation and renal failure. Journal of Medical Microbiology 15, 117-121.

Hardy, C., Lowes, J. A., Bansal, A. \& George, C. F. (1984). Salmonella meningitis following treatment of enteritis with neomycin. Postgraduate Medical Journal 60, 284-286.

Hook, E. W. (1985). Salmonella species (including typhoid fever). In Principles and Practice of Infectious Diseases (eds. G. L. Mandell, R. G. Douglas and J. E. Bennett), 2nd ed, pp. 1256-1267. USA : J. Wiley and Sons.

MacCready, R. A., Reardon, J. P. \& Saphra, I. (1957). Salmonella in Massachusetts. A sixteen year experience. New England Journal of Medicine 256, 1121-1128.

Rowe, B. \& Threlfall, E. J. (1986). Antibiotic resistance in salmonella. PHLS Microbiology Digest 3, 23-25.

SaPhra, I. \& Wasserman, M. (1954). Salmonella choleraesuis. A clinical and epidemiological evaluation of 329 infections identified between 1940 and 1954 in the New York Salmonella Centre. American Journal of Medical Science 228, 525-533.

SaPHRA, I. \& Winter, J. W. (1957). Clinical manifestations of salmonellosis in man. New England Journal of Medicine 259, 1128-1134.

Todd, W. T. A. \& MURDOck, J. M. (1983). Salmonella virchow: a cause of significant bloodstream invasion. Scottish Medical Journal 28, 176-178.

Wermer, S. B., Humphrey, G. L. \& Kamae, I. (1979). Association between raw milk and human Salmonella dublin infection. British Medical Journal 2, 238-240.

Winocour, P. H., Williams, G. R., Boyd, J. F. \& Kennedy, D. H. (1985). Septic arteritis complicating salmonellosis. British Medical Journal 287, 972-973. 